\title{
ANNOUNCEMENT
}

An information exchange section of the Journal will be published in future issues as needed. Active experimenters interested in exchanging information on experimental methods, designs, instruments, electronic circuits, systems, and/or computer technology (hardware, software, bugs) are invited to submit a one-paragraph statement along with complete name and address to the Editor. Publication will be rapid (in some instances, the next issue of the Journal), and there will be no charge. Researchers wishing to purchase or sell materials must specify costs as well as responsibilities and arrangements for shipping. The Editor reserves the right to reject or edit any submission.

The proposed section is meant to serve as an avenue of communication for bits of information that are most often exchanged at professional meetings or informal gatherings. If it fails to fulfill that function, the section will be discontinued.

\section{THE NATIONAL CONFERENCE ON THE USE OF ON-LINE COMPUTERS IN PSYCHOLOGY ANNOUNCES THE FIRST ANNUAL STUDENT PAPER COMPETITION}

Papers may be submitted across a broad range of computer-related topics, including, but not limited to: (a) innovative programming for on-line research, for simulation models, or for statistical procedures; (b) innovative hardware design for computer configurations, for peripheral devices, or for interface and communication networks; (c) applications of computers to psychology in new experimental paradigms, stimulus generation, or response collection procedures. Papers may be theoretical, experimental, and/or applied in approach. Eligibility is limited to (a) work done by a student currently enrolled in courses or (b) work done as a part of course, thesis, or other student research by a person who graduated within the year preceding the 1978 Conference. The author of the winning paper will be invited to address the 1978 Conference and will receive a complimentary year's membership in the Conference, a complimentary 1-year subscription to Behavior Research Methods \& Instrumentation, and a $\$ 50$ cash prize.

\section{DEADLINE: AUGUST 1, 1978}

Authors must submit six copies of the full paper. A cover sheet should include the author's name, mailing address, telephone number, academic affiliation, a 50-word abstract, and a self-addressed stamped postcard and envelope. Send these materials to the 1978 Program Committee Chairman:

\author{
Dr. John Cotton \\ Department of Education \\ University of California \\ Santa Barbara, California 93106 \\ Phone: (805) 961-3101 or 2494
}

